\title{
Unexplained apnoea and loss of consciousness during sub arachnoid block for caesarean section
}

\author{
Acharya $\mathrm{SP}^{1}$, Marhatta $\mathrm{MN}^{2}$, Amatya $\mathrm{R}^{3}$ \\ ${ }^{1}$ Lecturer, ${ }^{2}$ Associate Professor and Head, ${ }^{3}$ Professor, Department of Anesthesiology, Institute of Medicine, Maharajgunj, \\ Nepal.
}

\begin{abstract}
Sub arachnoid block (SAB) is often perceived safe by many anesthesiologists and other faculties but is also not completely safe choice especially in pregnant females, as the incidence of complications and local anaesthetic agent toxicity is high in these groups of patients. Here we present four such cases out of the seventeen patients over a period of six months, who developed apnea and transient loss of consciousness after spinal anesthesia for lower segment caesarean section. Typically all these patients after spinal anesthesia developed difficulty in breathing, became apnoea and had loss of consciousness for about a minute or two. The apnea was relieved with bag and mask ventilation following which the patient regained consciousness and start breathing normally. The rest of the procedure was uneventful. We presented these cases with aim of sharing similar experiences, and to aware about the possibility of such events as these events do occur frequently but case reports and literatures are unavailable.
\end{abstract}

Key words: Apnoea, loss of consciousness, lower segment caesarean section (LSCS), Sub arachnoid block (SAB).

\section{First Case}

A 25 yr female of Gravida $(\mathrm{G})_{2}$ Parity $(\mathrm{P})_{1+0}$ at $\mathrm{A}_{4}{ }^{+}$wks pregnancy with previous LSCS, was planned for elective LSCS. She had undergone open cholecystectomy under general anesthesia five yrs back and also had Emergency LSCS under SAB 3 yrs back for non-progress of labor, without any complications. During this pregnancy, she had regular antenatal visits, and had no other significant past history. On examination, her weight was $52 \mathrm{kgs}$, BP was $110 / 60 \mathrm{mmHg}$, pulse $86 /$ min, without any other significant findings. Neck, Spine, temporomandibular joint (TMJ) was normal, Mallampatti Grade II, Thyromental distance was adequate. On investigation, her haemoglobin was13.7 gm/dl, Blood group B + VE, Blood counts were normal, BT: 3', CT: 6', Urea: $2.4 \mathrm{mmol} / \mathrm{L}$, Creatinine: $58 \mathrm{mmol} /$ L, RBS: $4.6 \mathrm{mmol} / \mathrm{L}$, Sodium: $133 \mathrm{mmol} / \mathrm{L}$, Potassium: $4.0 \mathrm{mmol} / \mathrm{L}$. So patient was categorised as American Society of Anaesthesiologists (ASA) Grade I.

On the morning of surgery, intra venous (IV) cannulation done on dorsum of left hand with $18 \mathrm{G} \mathrm{IV} \mathrm{cannula} \mathrm{and}$ preload was done with $15 \mathrm{ml} / \mathrm{kg}$ of Ringers Lactate (RL), and urinary bladder catheterisation done with Foleys catheter.

In the operating room, ECG, Pulse Oxymeter, BP Cuff was attached. Sub arachnoid block was done at 9:50 am under aseptic precaution, in sitting position, midline approach with $25 \mathrm{G}$ Quincke's spinal needle at L3 - L4 inter vertebral space, with $2.0 \mathrm{ml}$ of $0.5 \%$ heavy Bupivacaine slowly. The patient was then made supine and bed tilted to left and oxygen was given through nasal prongs at $2 \mathrm{~L} / \mathrm{min}$. After five minutes, highest level of sensory block was checked with cold swab and pin prick, and was found at T6. Painting and draping was done and surgery was started at 10:02 am. At that time BP was $115 / 70 \mathrm{mmHg}$. There were no episodes of hypotension, SBP: $100-110 \mathrm{mmHg}$, HR was $90-110$ / min, $\mathrm{SPO}_{2}: 96-99 \%$. Alive female baby was delivered at 10:12 AM, with APGAR 7/10. Then Inj. Oxytocin $10 \mathrm{U}$ in remaining $200 \mathrm{ml}$ of RL. At 10:25 am, patient complained of foreign body sensation in the throat, followed by discomfort in the neck and difficulty in breathing. She was advised to take deep breaths through mask. Her blood pressure was 110/70 mmHg. Suddenly the patient was staring and was unresponsive to painful stimulus. $\mathrm{SpO}_{2}$ decreased to $93 \%$, then $89 \%$. Bag and mask ventilation was started, HR decreased from 108 to 70 , then $61 / \mathrm{min}$, BP was $104 / 60 \mathrm{mmHg}$. After around

Correspondence

Dr. Subhash Prasad Acharya,

Kaushaltar - 15, Madhyapur, Thimi,

Kathmandu, Nepal.

E-mail: drsuvash@gmail.com 
one min of bag and mask ventilation, $\mathrm{SpO}_{2}$ started to increased and reached $99 \%$, HR increased to 76 , then $118 / \mathrm{min}$, and SBP increased to $120 \mathrm{mmHg}$. While preparing for intubation, she gained her consciousness and was breathing spontaneously, with adequate tidal volume. Level of sensory block was rechecked and was at T5. Rest of the procedure and postoperative period was uneventful.

\section{Second case}

A 22 yr female $G_{2} P_{1}$ at $39^{+}$wks pregnancy with moderate meconium stained liquor with fetal distress, planned for emergency LSCS. Her first child was a normal vaginal delivery at hospital, and during this pregnancy she had regular antenatal visits without any complications. There were neither previous anaesthetic exposure nor any significant past history. On examination, her weight was $59 \mathrm{kgs}$, BP was 110/70 $\mathrm{mmHg}$, pulse $92 / \mathrm{min}$, without any other significant findings. Neck, Spine, TMJ was normal, Mallampatti Grade II, Thyromental distance was adequate. On Investigation, her hemoglobin was $11.5 \mathrm{gm} / \mathrm{dl}$, Blood group $\mathrm{A}+\mathrm{VE}$, Blood counts were normal, BT: 4', CT: 6'30', Urea: $3.5 \mathrm{mmol} / \mathrm{L}$, Creatinine: $78 \mathrm{mmol} / \mathrm{L}$, RBS: $6.5 \mathrm{mmol} / \mathrm{L}$, So patient was ASA Grade I E.

Just before the surgery, IV cannulation done on dorsum of left hand with $18 \mathrm{G} \mathrm{IV} \mathrm{cannula} \mathrm{and} \mathrm{preload} \mathrm{was}$ started with $15 \mathrm{ml} / \mathrm{kg}$ of Ringers Lactate, but only $500 \mathrm{ml}$ was infused, and urinary bladder catheterization done with Foleys catheter.

In the operating room, ECG, Pulse Oxymeter, BP Cuff was attached. Sub arachnoid block was done at 1:20 pm, under aseptic precaution, in sitting position, midline approach with $25 \mathrm{G}$ Quincke's spinal needle at L3 L4 inter vertebral Space, with $2.2 \mathrm{ml}$ of $0.5 \%$ Heavy Bupivacaine slowly. The patient was then made supine and bed tilted to left and oxygen was given through nasal prongs at $2 \mathrm{~L} / \mathrm{min}$. SBP decreased to $84 \mathrm{mmHg}$, so Inj Mephentermine $6 \mathrm{mg}$ IV Bolus given and rate of IV fluid infusion was increased. Then after there were no episode of hypotension. After five min, highest level of sensory block was checked with cold swab and pin prick, and was found at T4. Then painting and draping was done and surgery was started at 1:27 pm. SBP was maintained 100-110mmHg, HR: $118-102 / \mathrm{min}, \mathrm{SPO}_{2}$ : $97-99 \%$. Alive male baby delivered at 1:32 pm with APGAR 8/10. Then Inj. OXYTOCIN 5 U IV Bolus and $10 \mathrm{U}$ in remaining $300 \mathrm{ml} \mathrm{RL}$ were administered. At $1: 37 \mathrm{pm}$, suddenly the patient was staring and extended her right hand as if to grasp something and became apnoeic and unconscious. Bag and mask ventilation was started. $\mathrm{SpO}_{2}$ decreased to $78 \%$, HR was maintained at 110/min, SBP was $100 \mathrm{mmHg}$. All parameters improved after two mins of bag and mask ventilation. After this she was conscious and was breathing spontaneously and vitals were maintained through out the surgery. Highest level of sensory block was rechecked and was at T4 -T5. Then the procedure was uneventful till the postoperative period, except for the baby who had swallowed meconium and was taken to Neonatal ward and Stomach wash done, but was otherwise normal.

\section{Third case}

A $21 \mathrm{yr}$ female, primi at $38^{+}$wks pregnancy with fetal distress was planned for Emergency LSCS. She had regular antenatal visits and had no problems during pregnancy. In the past, she had tubercular lymhadenitis and treated with ATT for Nine months when she was 14 yrs old. There was neither previous anesthetic exposure nor any other significant past history. On examination, her weight was $49 \mathrm{kgs}$, BP was 120/68 mmHg, pulse $103 / \mathrm{min}$, without any other significant findings. Neck, Spine, TMJ was normal, Mallampatti Grade III, Thyromental distance was adequate. On investigation, her hemoglobin was $12.6 \mathrm{gm} / \mathrm{dl}$; Blood group A + VE, Blood counts, urea, creatinine, and sugar all were within normal limits. So patient was ASA Grade I E.

Before the surgery, IV cannulation done on dorsum of right hand with $18 \mathrm{G}$ IV cannula and preload was started with Ringers Lactate (only $300 \mathrm{ml}$ was infused), and urinary bladder catheterization done with Foleys catheter.

In the operating room, ECG, Pulse Oxymeter, BP Cuff was attached. Sub arachnoid block was done at 1:10 $\mathrm{pm}$, under aseptic precaution, in left lateral position, midline approach with 25 G Quincke's spinal needle at L3 - L4 inter vertebral space, with $2.0 \mathrm{ml}$ of $0.5 \%$ heavy Bupivacaine slowly. The patient was then made supine and bed tilted to left and oxygen was given through nasal prongs at $2 \mathrm{~L} / \mathrm{min}$. SBP decreased to $76 \mathrm{mmHg}$, so Inj Mephentermine $6 \mathrm{mg}$ IV Bolus given and rate of IV fluid infusion was increased. Then after SBP increased to $96 \mathrm{mmHg}$, then again SBP decreased to $82 \mathrm{mmHg}$, and Inj. Mephentermine $6 \mathrm{mg}$ IV was repeated again, and SBP increased to $106 \mathrm{mmHg}$, HR was $120 / \mathrm{min}, \mathrm{SPO}_{2}: 97-99 \%$. Then there were no episode of hypotension. After five min, highest level of sensory block was checked with cold swab and pin prick, and was found at T5. Then painting and draping was done and surgery was started at 1:18 pm. SBP was maintained 100 - 110mmHg, HR: $118-102 / \mathrm{min}, \mathrm{SPO}_{2}$ : $97-99 \%$. Alive male baby delivered at $1: 25 \mathrm{pm}$ with APGAR 7/10. Then Inj. Oxytocin 5 U IV Bolus and $10 \mathrm{U}$ in remaining $500 \mathrm{ml} \mathrm{RL}$ were administered. At $1: 30 \mathrm{pm}$, suddenly the patient complained of discomfort and was advised to take deep breaths. She then tried to grasp something, was sweating, started to stare and was unresponsive, became apnoeic and unconscious. 
Bag and mask ventilation was started. $\mathrm{SpO}_{2}$ decreased to $78 \%$, HR was maintained at $110 / \mathrm{min}$, SBP was 70 $\mathrm{mmHg}$ and thus Inj. Mephentermine $6 \mathrm{mg}$ and again 6 $\mathrm{mg}$ was given IV and rapid administration of IV fluid was done. Vital signs improved after 2-3 mins of bag and mask ventilation. After bagging, $\mathrm{SpO}_{2}$ Increased to $99 \%$, HR maintained $>115 / \mathrm{min}$, SBP maintained $>100$ $\mathrm{mmHg}$. After this she was conscious and was breathing spontaneously and vitals were maintained through out the surgery. Sensory level was rechecked and was at T5 - T6. Post operative periods were also uneventful.

\section{Fourth case}

A 24 yr female $\mathrm{G}_{2} \mathrm{P}_{0+1}$ at $38^{+}$wks pregnancy with fetal distress was planned for Emergency LSCS. She had regular antenatal visits and had no problems during pregnancy. There was neither anaesthetic exposure nor any other significant past history.

On examination, her weight was $61 \mathrm{kgs}$, BP was $114 / 66$ $\mathrm{mmHg}$, pulse $97 / \mathrm{min}$, without any other significant findings. Neck, Spine, TMJ was normal; Mallampatti Grade I, Thyromental distance was adequate. On investigation, her hemoglobin was $14.5 \mathrm{gm} / \mathrm{dl}$; Blood group $\mathrm{AB}+\mathrm{VE}$, Blood counts, urea, creatinine, and sugar all were within normal limits. So patient was ASA Grade I E.

Before the surgery, IV cannulation done on dorsum of left hand with $18 \mathrm{G} \mathrm{IV} \mathrm{cannula} \mathrm{and} \mathrm{preload} \mathrm{was}$ done with $15 \mathrm{ml} / \mathrm{kg}$ Ringers Lactate $(1000 \mathrm{ml}$ infused) and urinary bladder catheterization done with Foleys catheter.

In the operating room, ECG, Pulse Oxymeter, BP Cuff was attached. Sub arachnoid block was done at 2:55 pm, under aseptic precaution, in left lateral position, midline approach with $25 \mathrm{G}$ Quincke's spinal needle at L3 - L4 inter vertebral space, with $2.2 \mathrm{ml}$ of $0.5 \%$ heavy Bupivacaine slowly. The patient was then made supine and bed tilted to left and oxygen was given through nasal prongs at $2 \mathrm{~L} / \mathrm{min}$. At $5 \mathrm{~min}$, highest level of sensory block was identified at T5, SBP was $110 \mathrm{mmHg}$, HR: 108/min, $\mathrm{SPO}_{2}: 97-99 \%$. Then painting and draping was done and surgery was started at 3:01 pm. Alive male baby was delivered at 3:10 pm with APGAR 8/10. Inj. OXYTOCIN $15 \mathrm{U}$ in remaining $350 \mathrm{ml} \mathrm{RL}$ was administered. At 3:16 pm, the patient complained of difficulty in breathing and generalized discomfort and was given $100 \%$ oxygen through mask and was advised to take deep breaths. Soon she was unresponsive and became apnoeic and unconscious. Bag and mask ventilation was started, $\mathrm{SpO}_{2}$ decreased to $87 \%$, HR: $76 \mathrm{bpm}$. (c/f $108 \mathrm{bpm}$ ), SBP was maintained around $104 \mathrm{mmHg}$. After one to two minutes of bag and mask ventilation, $\mathrm{SpO}_{2}$ Increased to $99 \%$, HR maintained $>$ $100 / \mathrm{min}, \mathrm{SBP}$ maintained $>100 \mathrm{mmHg}$. Then she was conscious and was breathing spontaneously, and vitals were maintained for the rest of the surgery. Level of sensory block was checked again and was at T4. Post operative periods were uneventful.

\section{Discussion}

As seen with all these cases, the event is more or less similar but what could be the possible causes or explanation for such events.

Kety et $\mathrm{al}^{1}$. showed that producing spinal anesthesia to midthoracic levels with procaine, even in patients with essential hypertension, resulted in a decrease in mean arterial pressure of 26 percent (155 to $115 \mathrm{mmHg}$ ) but along with only 12 percent (52 to $46 \mathrm{ml} / 100 \mathrm{~g} / \mathrm{min}$ ) decrease in cerebral blood flow. Caplan et al. ${ }^{2}$ identified fourteen cases of sudden cardiac arrest in healthy patients receiving spinal anesthesia. As these cases seemed to appear suddenly after stable hemodynamic status, they concluded that a poorly understood potential exists for sudden cardiac arrest even in healthy patients. It is also clear that hypoxemia and over sedation are not required for severe bradycardia and asystole to develop during well-conducted spinal anesthesia ${ }^{3}$. It is also clear that the development of severe bradycardia following spinal anesthesia is not a new phenomenon and has been recognized for many years ${ }^{4,5}$. Changes in pulmonary variables in healthy patients during spinal anesthesia are usually of little clinical consequence. Tidal volume remains unchanged during high spinal anesthesia, and vital capacity decreases a small amount from 4.05 to $3.73 \mathrm{~L}^{6}$. The rare respiratory arrest associated with spinal anesthesia is also unrelated to phrenic or inspiratory dysfunction, but rather to hypoperfusion of the respiratory centers in the brain stem. Supportive evidence for this concept is observed after resuscitation, when apnea almost always disappears as soon as pharmacologic and fluid therapies have restored cardiac output and blood pressure. This would not be the case if phrenic paralysis due to high levels of local anesthetic were the cause of apnea ${ }^{7}$. Intraoperatively, if high spinal anesthesia occurs, patients occasionally complain about dyspnea excessively. This is not because of significantly decreased inspiratory capacity but most often related to loss of chest wall sensation. This does not allow patients to experience the reassurance of a deep breath. This disturbance of acceptance of the patient can often be overcome by instructing the patients to raise a hand near the mouth and exhale forcefully. The tactile appreciation of the deep breath provides reassurance. Nausea and vomiting may be associated with sub arachnoid block in up to 20 percent of patients and is primarily related to GI hyperperistalsis due to unopposed parasympathetic 
(vagal) activity ${ }^{8}$. Despite predictable decreases in renal blood flow accompanying centroneuraxis block, the decrease is of little physiologic importance.

Analysing, individual causes for the transient apnea, following are the commonly thought about possibilities and views for and against it.

Hypotension leading to brainstem hypo-perfusion (could have been undetected) and thus transient apnea was the most likely cause ${ }^{9,10}$. But, hypotension was not present in all cases. In most cases blood pressures were maintained.

Higher level of motor blockade or total spinal block can cause apnea due to intercostal muscle paralysis, and is more common in patients with compromised lung functions ${ }^{9}$. But in our patients, highest sensory block was T2 in one and T4 in others, level of sensory block was not high in all cases, and also there were no other features of total spinal block. The apnea that occurred was also for a transient period and improved immediately with manual ventilation, which in case of high block would be for a longer period of time?

Bhati FS et al also reported a 25 year old parturient who had loss of consciousness occurred after 12 mins of injection of intrathecal lignocaine ${ }^{11}$. Chan YK et al also reported another case with transient loss of consciousness after 20 mins of administration of intrathecal bupivaciane ${ }^{12}$. The authors attributed the transient loss of consciousness to a possibility of a subdural block. But in the cases we observed, the possibility of subdural injection was less likely because the duration of apnoea was transient and there was no motor block in the higher segments after regaining of consciousness.

It has also been explained that after subarachnoid block, along with the nerve fibers, some ascending pathways like fibers of spino-reticular tracts are also blocked by the anesthetic agents leading to inhibition of peripheral impulses that are carried to the reticular activating system thus causing drowsiness, sedation and sometimes even loss of consciousness 9 .

Another possibilities are impurities in the Heavy Bupivacaine used. In some cases, ANAWIN (Neon) were used while in others SENSORCAINE (Astra Zeneca). Irrespective of the brand used, apnea occurred. If the apnea was due to the agent, it should have occurred in all cases when same batch of drug was used, but it was not so. Apnea occurred in sporadic cases only and also there are no literatures to suggest so. Thus it requires more studies comparing various spinal anaesthetic agents from different manufacturers. In almost all of the cases, apnea occurred only after Oxytocin was given, thus apnea could be due to hypotension caused by indirect action of Oxytocin. Hypotension occurs more when Oxytocin is given as intravenous bolus and less when given in infusion. Or, this could also be due to respiratory side effects of Oxytocin, causing apnea; however, there are no literatures to support this.

In conclusion, apnea seems to be due to interplay of all these factors rather than because of a sole cause. Literatures support either of these causes as a possibility for apnea during sub arachnoid block for Cesarean section but the exact cause remains a Quagmire.

\section{References}

1. Kety SS, King BD, Horvath SM et al. The effects of an acute reduction in blood pressure by means of differential spinal sympathetic block on the cerebral circulation of hypertensive patients. J Clin Invest. 1950; 29:403.

2. Caplan RA, Ward RJ, Posner K, Cheney FW. Unexpected cardiac arrest during spinal anesthesia. A closed claims analysis of predisposing factors. Anesthesiology. 1988; 68:5.

3. Mackey DC, Carpenter RL, Thompson GE et al. Bradycardia and asystole during spinal anesthesia: a report of three cases without morbidity. Anesthesiology. 1989; 70:866.

5. Thompson KW. Fatalities from spinal anesthesia. Anesth Analg. 1934; 13:75-9.

6. Wetstone DL, Wong KC. Sinus bradycardia and asystole during spinal anesthesia. Anesthesiology. 1974; 41:87.

7. Egbert LD, Tamersoy K, Deas TC. Pulmonary function during spinal anesthesia: the mechanism of cough depression. Anesthesiology. 1961; 22:882.

8. Greene NM. Perspectives in spinal anesthesia. Reg Anesth. 1982; 7:55.

9. Birnbach DJ, Browne IM. Anesthesia for Obstetrics. Inc Miller's Anaesthesia. 6th Edition. UK: Elsevier; 2005. P. 2307-44.

10. Morgan, Mikhail and Murray Editors Obstetrics Anesthesia. Inc Clinical Anaesthesiology. 3rd Edition. US: McGraw Hill; 2002.

11. Bhati FS, Vijayvergia VK, Jain VL, Sharma M. Loss of consciousness following spinal anaesthesia for cesarean section - a case report. Indian Journal of Anaesth. 2004; 48 (1): 57-8.

12. Chan YK, Gopinathan R, Rajendram R. Loss of consciousness following spinal anaesthesia for caeserean section. BJA. 2000; 85: 474-6. 